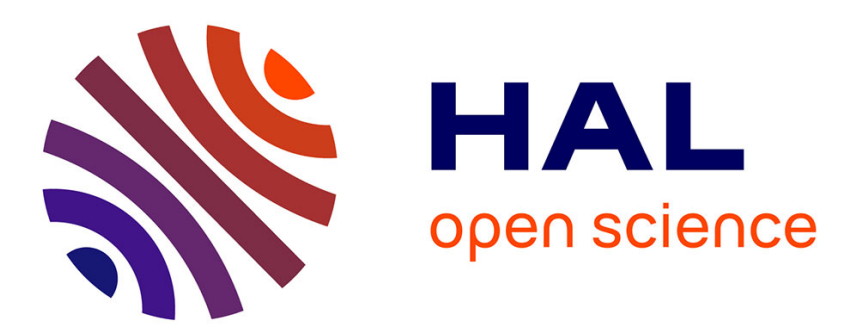

\title{
Aerosol generated mesoporous silica particles
}

Niki Baccile, David Grosso, Clément Sanchez

\section{To cite this version:}

Niki Baccile, David Grosso, Clément Sanchez. Aerosol generated mesoporous silica particles. Journal of Materials Chemistry, 2003, 13 (12), pp.3011-3016 10.1039/B307757H . hal-01455145

\section{HAL Id: hal-01455145 \\ https://hal.sorbonne-universite.fr/hal-01455145}

Submitted on 3 Feb 2017

HAL is a multi-disciplinary open access archive for the deposit and dissemination of scientific research documents, whether they are published or not. The documents may come from teaching and research institutions in France or abroad, or from public or private research centers.
L'archive ouverte pluridisciplinaire HAL, est destinée au dépôt et à la diffusion de documents scientifiques de niveau recherche, publiés ou non, émanant des établissements d'enseignement et de recherche français ou étrangers, des laboratoires publics ou privés. 


\title{
IMPORTANT NOTE: Please be aware that slight modifications occurring after Proof correction may occur between this version of the manuscript and the version on the
}

\section{Aerosol generated mesoporous silica particles}

\author{
Niki Baccile, David Grosso and Clément Sanchez* \\ Laboratoire Chimie de la Matière condensée, Université Pierre et Marie Curie (Paris VI) -- CNRS, 4, Place \\ Jussieu (T54-E5), 75252 Paris CEDEX 05, France. Fax. +33 (1) 44.27.47-69 - Tel. +33 (1) 44.27.33.65 - E- \\ mail.clems@ccr.jussieu.fr
}

This submission was created using the RSC Article Template (DO NOT DELETE THIS TEXT)
(LINE INCLUDED FOR SPACING ONLY - DO NOT DELETE THIS TEXT)

Organized mesoporous silica sub-micro spheres have been synthesized by spray drying solutions containing hydrated $\mathrm{Si}(\mathrm{OEt})_{4}$ as silica precursor and surfactants as texturing agent. The resulting powder exhibits controlled organized 2-D hexagonal honey-comb like porosity of 2,2 $\mathrm{nm}$ mean pore diameter, homogeneous size dispersion (the particle average diameter is around 0,3 $\mu \mathrm{m}$ and standard deviation $\sigma=1,89)$, and a high specific surface area $\left(1000 \mathrm{~m}^{2} / \mathrm{g}\right)$. The long-range order porosity was achieved after controlling different parameters: surfactant type and surfactant/TEOS ratios, dilution, $\mathrm{pH}$, temperature and relative humidity under laminar flux motion conditions of aerosol generation. Powders were characterized using X-ray diffraction, TEM, $\mathrm{N}_{2}$ isotherm adsorption/desorption cycles and FTIR.

\section{Introduction}

During the last ten years that followed the discovery of meso-organised templated materials by Mobil \& Co. ${ }^{1}$, many groups developed novel nano-textured inorganic and organic/inorganic hybrid materials by combining the sol-gel chemistry and the structuring effect of self assembling liquidcrystal surfactants. Most of those works, to which a number of reviews has been dedicated ${ }^{2,3,5}$, focused on the precipitation in solution of silica based oxide networks around a great variety of charged surfactants ${ }^{1,9}$ such as Cethyltriethylammonium Bromide (CTAB) or amphiphile block co-polymers such as PEO-PPOPEO Pluronics ${ }^{6,7,8}$. Once the template is removed from the framework through thermal treatment or solvent extraction, the porosity stands at the former location of the nano-segregated micelles. This technique allows a perfect control of the pore size (typically between 2,1 and $10 \mathrm{~nm}$ in diameter depending on the surfactant molecular weight) and a controlled pore morphology and self organization within the material (spheres, cylinders or

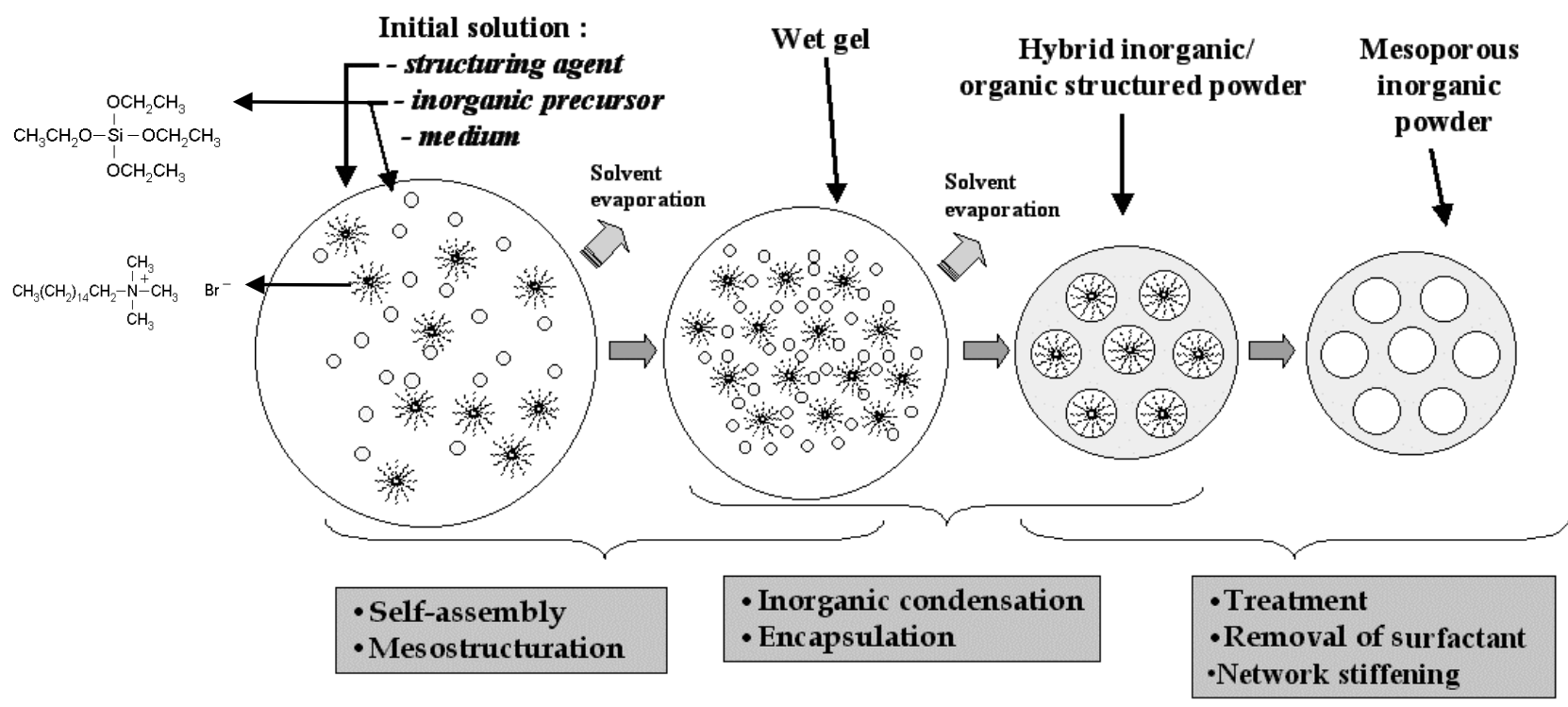

Inorganic condensation via

Hydrolysis $(\mathrm{RO})_{3}-\mathrm{Si}-\mathrm{OR}+\mathrm{H}_{2} \mathrm{O} \rightleftharpoons(\mathrm{RO})_{3}-\mathrm{Si}-\mathrm{OH}+\mathrm{ROH}$. Sol-gel chemistry:

$$
\text { Condensation }(\mathrm{RO})_{3}-\mathrm{Si}-\mathrm{OH}+\mathrm{HO}-\mathrm{Si}(\mathrm{RO})_{3} \gtreqless \text {-Si-O-Si- }+\mathrm{H}_{2} \mathrm{O}
$$

Fig. 01 The process of spray dried mesoporous silica particles. The initial droplet contains Cetyltrimetilammonium bromide (CTAB) as structuring agent, Tetraethoxysilane (TEOS) as silica precursor. The inorganic condensation is achieved via the sol-gel process, whose fundamental steps are showed in the low part of the picture. The role of solvent evaporation in the mesostructuration is put in evidence. 
lamellae organized into mono-, bi-, or tri-dimensional arrays). In other words, surfactant micelles play the role of template of the porous network whose geometry is directly related to the surfactant molecule morphology ${ }^{10}$ and concentration in the medium $^{11}$.

Figure 01 illustrates the various steps involved in such a synthesis route. More recently, this technique was adapted to thin films, monoliths, and macro-spheres preparation through a controlled evaporation of initial isotropic mixtures of surfactant molecules and inorganic precursors in an appropriated highly volatile solvent. This new approach, addressed as the Evaporation Induced Self Assembly technique ${ }^{12}$ (EISA), has great advantages over the precipitation one. Indeed, firstly the surfactant/silica stoichiometry is retained along evaporation; secondly the shaping into spheres takes place with a control on the diameter (aerosol); thin layers have a controlled thickness (liquid deposition) and finally large objects with controlled dimensions (slow evaporation) are possible. While powder precipitation has been well developed, the EISA method was firstly directed to the preparation of variously mesostructured and porous silica thin films ${ }^{12}$, which are interesting materials for applications in catalysis ${ }^{13,14,15}$, separation ${ }^{16}$, optoelectronic ${ }^{17}$ and chemical sensing ${ }^{18}$.

The mechanisms involved during self-assembly were studied in details on thin films systems and are now well understood ${ }^{4,19,20,21,22}$. Critical parameters that govern the mesoporosity are the surfactant volume fraction, the inorganic extent of condensation when processing, the evaporation conditions such as humidity and the post synthesis thermal treatment aiming at eliminating the surfqctqnt and stiffening the inorganic network.

Powders have indeed important applications in catalysis and separation domains but control on the primary particle dimension remains a challenge in precipitation synthesis. An alternative path stands in the simple, industrially already well developed and cheap aerosol generation of particles in which the EISA follows the similar evaporation and self-assembly laws than those for thin films.

Few works have been already dedicated to mesoporous spheres prepared by spray-drying. The first one was provided by the Sandia National Laboratory ${ }^{23}$ and concerns silica particles while the second was concerned the mesoporous crystalline anatase $\mathrm{TiO}_{2}$ homologue by Grosso et al. in $2003^{24}$. A third one has been published in 2003 by Bore and Coll. ${ }^{29}$. In this one, some more detailed informations about the influence of chemical parameters on the mesostructure were provided. Even if these works stretched out the enormous potential of combining spray drying to the template approach, none of them however gives detailed informations conceming the synthesis, the particle size dispersion and expecially the processing conditions and their influence on the mesostructure quality of the final rnaterial.

The present article is then dedicated to this topic and many future ones will undoubtedly follow. Typical silica mesoporous particles were prepared by hydrolysis and condensation of silicon alcoxide precursors ${ }^{25}$ in presence of $\mathrm{CTAB}$, as depicted in Figure 01, through controlled evaporation of spray generated droplets from an initial sol. After surfactant elimination by calcination, the material exhibited an excellent degree of meso-ordering, a high specific surface area of more than $1000 \mathrm{~m}^{2} \cdot \mathrm{g}^{-1}$, a narrow pore size distribution centered at 2.3 $\mathrm{nm}$ and an excellent thermal stability. The process was then optimized by studying the influence of the chemical parameters (CTAB/Si molar ratio, $\mathrm{pH}$, solvent quantity) and of the processing parameters (viscosity related to dilution, carrying gas composition, humidity percentage, pathway length). The optimal process was then extended to other silica particles templated with larger PEO-PPO-PEO block copolymers or $\mathrm{C}_{n} \mathrm{H}_{2 n+1} \mathrm{PEO}$ amphiphiles to enable larger organized pores. It is worthed to remark that the EISA process is easily extensible to spray coating.

\section{Experimental - preparation of particles}

The particles were synthesized by spraying solutions containing Tetraethylorthosilicate (TEOS), surfactants, water $(\mathrm{pH} 1,2)$, ethanol of molar ratios 1:x:40:30 (where $\mathrm{x}$ is equal to surfactant moles) after vigorous stirring for $1 \mathrm{~h}$. Four surfactants were used: $\mathrm{C}_{16} \mathrm{H}_{33} \mathrm{~N}\left(\mathrm{CH}_{3}\right)_{3} \mathrm{Br}-\mathrm{CTAB}-(0,35>\mathrm{x}>0,08)$; $\mathrm{C}_{16} \mathrm{H}_{33}(\mathrm{EO})_{20} \mathrm{H}-$ Brij $58-(\mathrm{x}=0,06)$; $(\mathrm{EO})_{20}(\mathrm{PO})_{70}(\mathrm{EO})_{20}-$ Pluronic P123 - ( $\mathrm{x}=0,0078)$, and $(\mathrm{EO})_{106}(\mathrm{PO})_{70}(\mathrm{EO})_{106}$ Pluronic F127 - $(\mathrm{x}=0,0035)$. The spray drying apparatus was composed of a constant out-put atomizer (TSI model 3076), nominally providing droplet particles of $2000 \mathrm{~nm}$ in mean diameters (typical dry particle mean diameters vary from 20 to $300 \mathrm{~nm}$ depending on the concentration), at a fixed gas pressure of $2.5 \cdot 10^{5} \mathrm{~Pa}$ and a flux of $3 \mathrm{lt} \cdot \mathrm{min}^{-1}$. Particles were then carried by the gas flux to different elements where they stayed for various lengths of time that were controlled by the tubing lengths and diameter. These elements are the following:

(1) A nitrogen cold trap aiming at eliminating the alcohol vapor from the system.

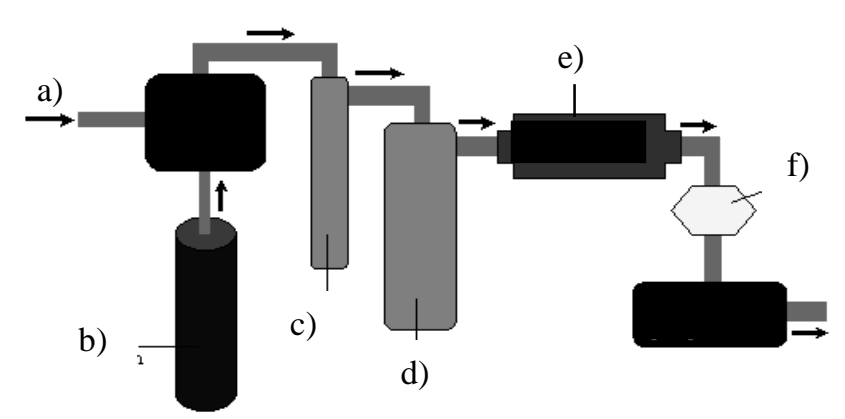

Fig. 02 Scheme of the aerosol apparatus generator; a) $\mathrm{N}_{2}$ gas injection at constant pressure and flow rate; b) initial solution container; c) liquid $\mathrm{N}_{2}$ ethanol trap; d) particles drying chamber; e) furnace at $350^{\circ} \mathrm{C}$; f) pparticles membrane filter paper

(2) A drying chamber aiming at giving time to the particles to equilibrate with their environment and eventually to selforganize.

(3) A cylindrical furnace allowing the densification of particle outer shell (crust layer) preventing any future coalescence.

(4) A $450 \mathrm{~nm}$ porous filter on which particles are collected.

(5) And finally a vacuum pump necessary to keep the flux constant in a laminar regime.

A global scheme is shown in Figure 02. Temperatures could be varied in the drying chamber and the oven and the relative humidity (RH) can be adjusted between 0 and $90 \%$ in the drying chamber. As-prepared powders were then thermally treated at $400{ }^{\circ} \mathrm{C}$ to eliminate the organic templating phase. FTIR spectroscopy investigation insured the total thermal degradation of the template (Figure 03).

The particles meso-texturation was deduced from $\mathrm{X}$ ray diffraction (XRD) in a $\theta-2 \theta$ geometry ( $\mathrm{Cu} k \alpha, \lambda=0,154 \mathrm{~nm}$ ) (Philips PW 1820) investigations and confirmed on the whole sample by Transmission Electron Microscopy (TEM) (Jéol 100 JX/STEM). The elementary particle size dispersion was estimated from Scanning Electronic Microscopy (SEM) by manual counting. The Porosity was fully characterized by $\mathrm{N}_{2}-$ adsorption-desorption BET investigations.

\section{Conditions of particle generation}

Particles were generated under a homogeneous and constant regime. The Reynold's number $\left(\mathrm{Re}_{t}\right)$ defines the regime of the particle transport within the system. $\operatorname{Re}_{\mathrm{t}}$ was calculated from $U$ (average gas velocity which is $2-3$ lt. $\mathrm{min}^{-1}$ ), the tube minimal diameter $\left(d_{t}=2 \mathrm{~cm}\right)$, the nitrogen gas density $(\rho)$ and 


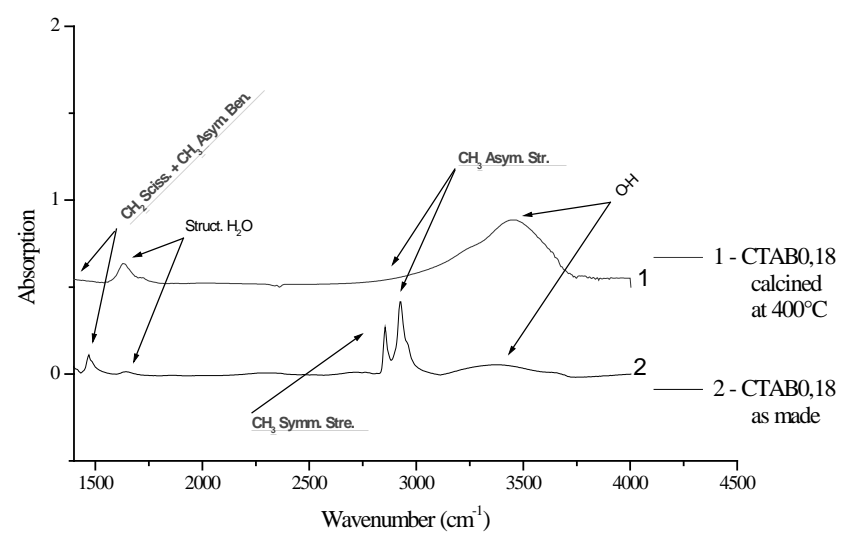

Fig. 03 IR Spectra compared between CTAB 0,18 as made and calcined at $400^{\circ} \mathrm{C}$ in the region $1500-4000 \mathrm{~cm}^{-1}$. The high adsorption peaks (calcined sample) in the $1600 \mathrm{~cm}^{-1}$ area are due to water condensation in the empty mesopores.

its viscosity $(\mu)$ at room temperature [Ref. 26, p.62] to be $\operatorname{Re}_{t} \approx$ 250 . Since $\operatorname{Re}_{t}<2100$, the particle transportation is done within the carrying gas into a laminar flux motion.

The particle generation follows a continuous regime since the Knudsen number has been evaluated to be $\left(0.001<\mathrm{K}_{\mathrm{n}}\right.$ $=2 \lambda / d_{p}<0,06$; from Ref. 26, p.23), where $d_{p}$ is the experimental particle diameter which decreases from 2 to $0.3 \mu \mathrm{m}$ by evaporation (in Figure 04 are reported the dried particle size distribution and a typical SEM picture of the particle is additionally provided) and $\lambda$ is the nitrogen mean free path $(\lambda=$ $\left(\mathrm{k}_{\mathrm{B}} \mathrm{T}\right) /\left(2^{1 / 2} \sigma^{2} \pi \mathrm{p}\right) \approx 0,0097 \mu \mathrm{m}, \mathrm{p}$ being the gas pressure inside the pipe of $(105 \mathrm{~Pa})$ and $\sigma$ the nitrogen molecular cross section at room temperature). In the continuous regime, particles are large enough to fully follow the carrying gas motion. Despite these ideal conditions of particle generation, we assume that $\sim 40$ $\%$ of the particles production rate (nominally given at $10^{7}$ particles $\mathrm{cm}^{-3}$ ) are lost within the system as a result of the gravitational force, the hydrophilic nature of the glass pipes, the thermophoresis phenomenon at the oven exit enhanced by the complexity of the piping pathway geometry (abrupt flow direction changes).

\section{Particle size distribution}

The initial droplet size distribution and mean average size are strictly bound to the solution viscosity and the atomizer characteristics (pressure, dimension of the membrane hole). Taking into account that the optimal initial solution contains weight ratios of $9 \%$ TEOS, $3 \%$ CTAB, $58 \%$ Ethanol, and $30 \%$ hydrochloric aqueous solution at $\mathrm{pH} \quad 1,2$ (TEOS/CTAB/Water/Ethanol $=1 / 0,18 / 40 / 30$ molar ratios $)$, and that the final particles are composed of $\mathrm{SiO}_{2}$ microporous framework $\left(\rho_{\mathrm{SiO} 2} \approx 1.8 \mathrm{~g} . \mathrm{cm}^{-3}\right)$ and CTAB micelles $\left(\rho_{\mathrm{CTAB}} \approx 1\right.$ g. $\mathrm{cm}^{-3}$ ), the volume fraction of non volatile, condensed matter present in the solution is $4 \%$. Since $V_{\text {part }} / V_{\text {drop }}=0.04=d_{p}{ }^{3} / d_{d}{ }^{3}$, then the $d_{p} / d_{d}=0.34$ suggests that any droplet is expected to reduce its size of a factor of 0.34 after drying, when keeping its integrity.

Figure 04 exhibits the SEM picture of a typical mesoporous silica powder prepared from a solution with the typical composition given above. The corresponding particle size distribution is also given. The lognormal mean particle diameter was evaluated at $d_{p}=0.29 \mu \mathrm{m}$ with a standard deviation $\sigma_{\mathrm{g}}=$ $1.89 \mu \mathrm{m}$ [Ref. 26, p.29]. These values suggest that the initial mean particle diameter is $0.29 / 0.34=0.85 \mu \mathrm{m}$. The nominal initial droplet diameter is given to be around $2 \mu \mathrm{m}$ for water solutions. Here, the lower theorical value of $0.85 \mu \mathrm{m}$ is likely related to the presence of $58 \%$ ethanol which reduces the solution viscosity. However, the value of $\mathrm{d}_{\mathrm{p}} \sim 0.29 \mu \mathrm{m}$ remains in respect with the nominal characteristics of the our atomizer.
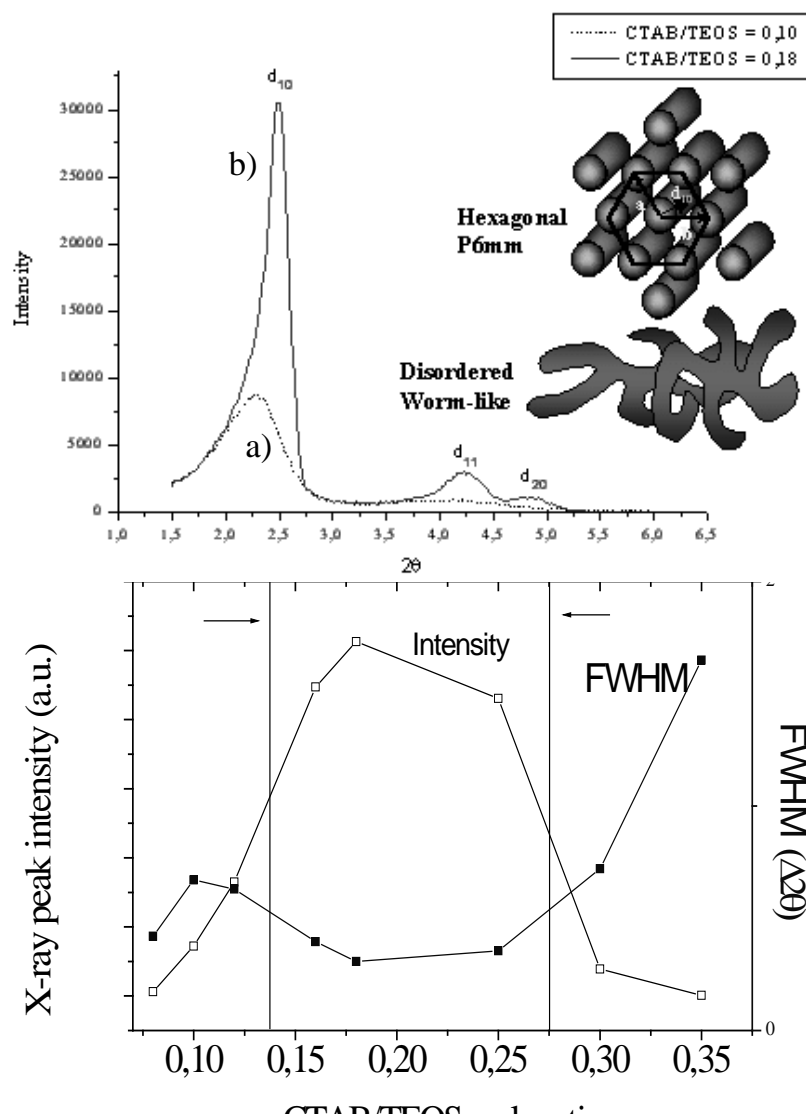

\section{$\mathrm{CTAB} / \mathrm{TEOS}$ mole ratio}

Fig. 05 Diffraction pattern of sample mole ratios (a) $\mathrm{CTAB} / \mathrm{TEOS}=0,10$ (worm-like structure) and (b) CTAB/TEOS $=0,18$ (P6mm structure). The hexagonal and worm-like micelle models are shown. The interplanar distance $d_{10}$ is given as well as the cell parameters a and b. Undeneath, diffraction pattern intensities and Full Width at Half Maximum (FWHM) of samples shown in Table 2 show that the highest organization is reached in the central region of the graph, when the intensity is maximized and the FWHM is minimized. 


\section{Mesostructure formation (influence of chemical parameters)}

The starting solution conditions have been chosen by taking into account the behaviour of TEOS silica precursor in ethanol/water mixtures well known in sol-gel chemistry. From previous studies on films it was demonstrated that optimal conditions of hydrolysis condensation exist to promote well organisation during EISA $^{21,27}$. Following these, the initial solution $\mathrm{pH}$ was fixed at 1,2 in order to favour high hydrolysis and low condensation rates, which enable highly hydrophilic but small silica entities within the solution during the pulverisation period. The optimal solvent composition and dilution were fixed at TEOS/Water/Ethanol $=1 / 40 / 30$ (molar ratios) as to minimize the loss of matter into the system and the pulverisation time, and to keep a good compromise between the extent of organisation, solution stability and concentration (based on a trial and error method). These optimal conditions are kept unchanged in the following study.

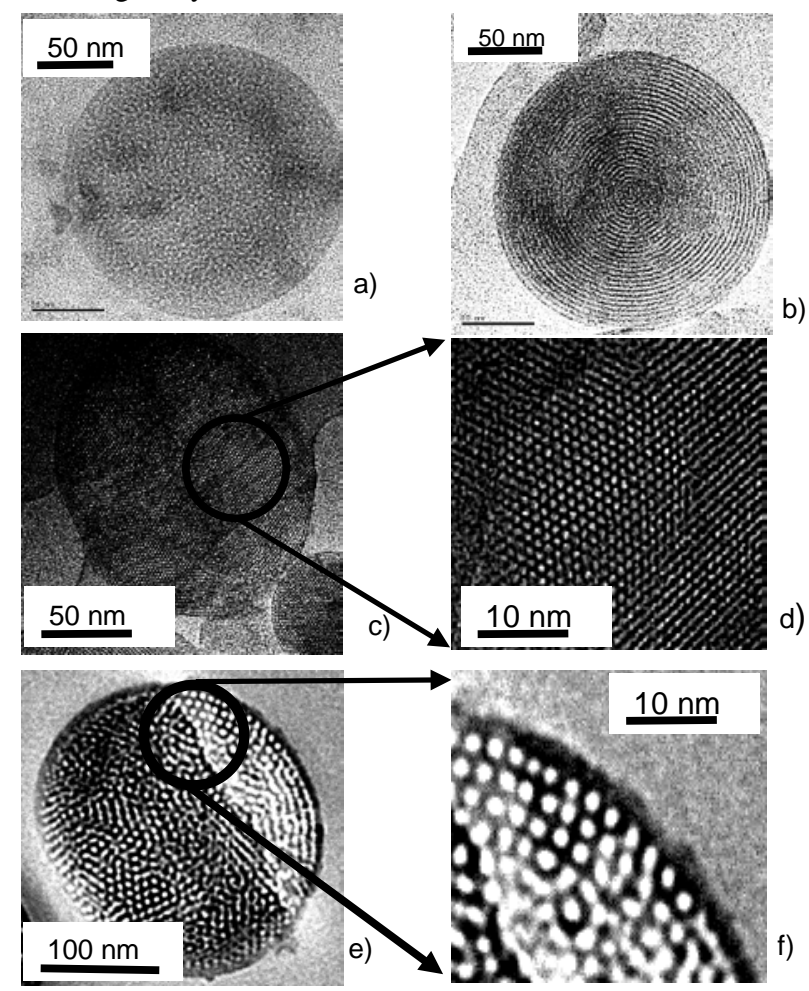

Fig. 06 TEM pictures of (a) worm-like mesophase and (b, c, d) 2-D hexagonal P6mm mesophase. Pictures b) and c) show respectively the micellar parallel planes and hexagonal micellar array. In figure d) the hexagonal honeycomb cell is detailed. Figures e) and f) show the cubic structure of Pluronic F127 templated silica.

As already reported for such systems ${ }^{20,23}$, the most important parameter that governs the formed mesophase is the $\mathrm{CTAB} / \mathrm{SiO}_{2}$ volume ratio, since a high concentration in surfactant tends to form low curved interfaces while low surfactant concentrations lead to highly curved micelles that promotes extended interface of interaction between both phases $^{10,11}$.

TABLE 1 gives a list of the samples synthesised at different surfactant ratios together with their corresponding structural characterisation deduced from XRD and $\mathrm{N}_{2}$-BET investigations. Figure 05 displays the $\mathrm{X}$-ray diffractions of (a) a typical worm-like structure, and (b) a typical 2D-Hexagonal structure (space group p6m) composed of cylindrical micelles which in the second case are organised into a compact hexagonal array. Peaks have been attributed to the (10), (11) and (20)
Miller indices of the hexagonal structures. The compact hexagonal structure is confirmed on the whole particle by TEM

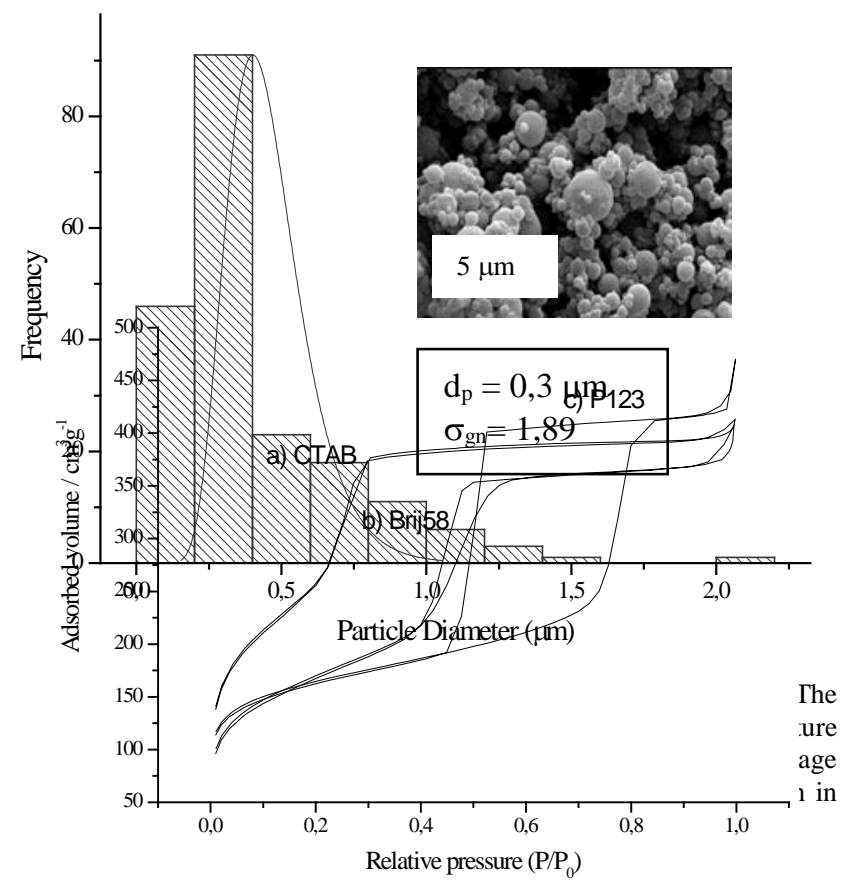

Fig. 07 BET isotherms for a) CTAB sample (type IVc), b) Brij 58 sample (type IV) and for c) P123 sample.

Table 01 Diffraction data, porosity characteristics and mesophase attribution for some CTAB/TEOS mole ratios

\begin{tabular}{|c|c|c|c|c|c|}
\hline $\begin{array}{c}\text { CTAB/TEOS } \\
\text { mole ratio }\end{array}$ & $\begin{array}{c}\text { FWHM } \\
(\Delta 2 \theta)\end{array}$ & $d_{10}(n m)$ & $\begin{array}{l}\text { Specific } \\
\text { pore } \\
\text { volume } \\
\left(\mathrm{cm}^{3} / \mathrm{g}\right)\end{array}$ & $\begin{array}{c}\text { Specific } \\
\text { surface } \\
\text { area } \\
(\mathrm{BET}) \\
\mathrm{g} / \mathrm{cm}^{3}\end{array}$ & Phase \\
\hline 0,08 & 0,42 & 4,29 & - & - & $\begin{array}{c}\text { Worm- } \\
\text { like }\end{array}$ \\
\hline 0,10 & 0,67 & 3,77 & 0,5 & 934 & $\begin{array}{c}\text { Worm- } \\
\text { like }\end{array}$ \\
\hline 0,12 & 0,63 & 3,81 & 0,6 & 1058 & $\begin{array}{l}\text { Worm- } \\
\text { like }\end{array}$ \\
\hline 0,16 & 0,40 & 3,74 & 0,6 & 1184 & $\begin{array}{l}2-\mathrm{D} \\
\text { Hex }\end{array}$ \\
\hline 0,18 & 0,31 & 3,53 & 0,7 & 1222 & $\begin{array}{l}2-\mathrm{D} \\
\text { Hex }\end{array}$ \\
\hline 0,25 & 0,36 & 3,45 & - & - & $\begin{array}{l}2-D \\
\text { Hex }\end{array}$ \\
\hline 0,30 & 0,72 & 3,07 & - & - & $\begin{array}{l}\text { Worm- } \\
\text { like }\end{array}$ \\
\hline 0,35 & 1,65 & 3,23 & - & - & $\begin{array}{c}\text { Worm- } \\
\text { like }\end{array}$ \\
\hline
\end{tabular}

as shown by the [001] and [110] view planes of Figures 06 (b,c and d) respectively, where one observes that the elongated micelles tend to align with the spherical particle surface in the hexagonal organisation, while they are randomly oriented in the worm-like structure (Figure 06 (a)). This was already observed in thin films where cylindrical micelles tends to align with both surface and substrate interfaces during evaporation ${ }^{20}$.

A typical CTAB templated $\mathrm{N}_{2}$-BET adsorptiondesorption isotherm is shown in Figure 07 (a). It reveals that the material is highly mesoporous with narrow pore size distribution centred at $2.2 \mathrm{~nm}$ in agreement with TEM observations. The 
silica wall between two pores was estimated to be close to $2 \mathrm{~nm}$ (calculated by subtraction of the pore diameter to the inter-planar distance, $\mathrm{d}_{10}$ ). The porosity was estimated to be above $0.5 \mathrm{~cm}^{3} \cdot \mathrm{g}$ 1 , and the specific surface area was calculated to be above 1000 $\mathrm{m}^{2} \cdot \mathrm{g}^{-1}$. These characteristics are similar to homologue materials prepared by precipitation ${ }^{1,28}$. The increase of the CTAB/TEOS ratio causes a shorter inter-micellar distance associated to a higher porosity and higher specific surface area, because of a

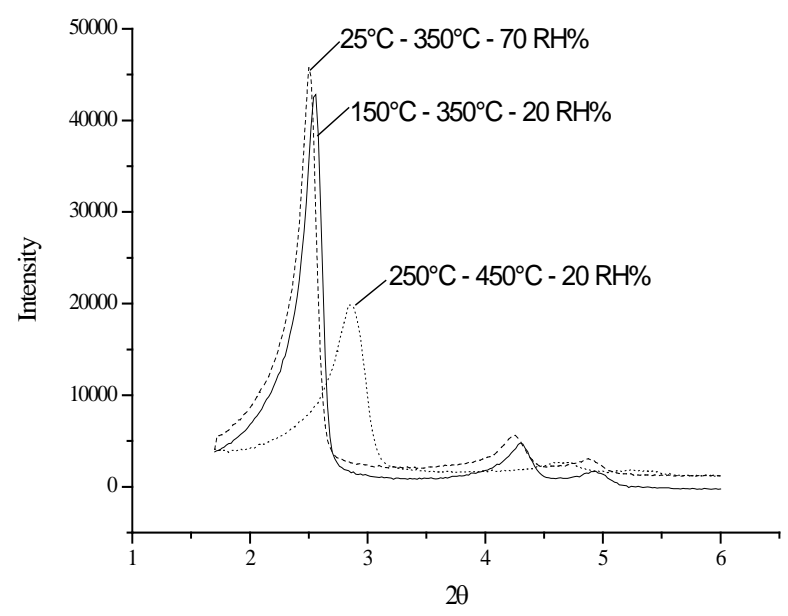

Fig. 08 X-ray pattern showing the influence of the aerosol pathway temperature and humidity. In the legend, the first temperature refers to the drying chamber, the second one refers to the furnace and the third value refers to the relative humidity percentage in the drying chamber.

larger surfactant volume fraction. The organisation into the $\mathrm{p} 6 \mathrm{~m}$ structure is verified for $\mathrm{CTAB} / \mathrm{Si}$ ratios ranging from 0.15 to 0.25 with an apex in the organisation degree located at 0.18 as illustrated in Figure 05. This optimal system will then be used to study the influence of the processing conditions on the organisation degree.

In order to create larger pores, we have used Pluronics as structuring agents and a tri-dimensional micellar Cubic structure was found, as shown by the corresponding TEM image in Figure 06 (e). The $\mathrm{N}_{2}$-BET adsorption-desorption isotherm of the P123 sample, shown in Figure 07 (c), is of type IV showing the presence of a large hysteresis loop of type $\mathrm{H}^{28}$, indicating that capillary condensation and evaporation do not take place at the same pressure, and that bottlenecks between pore arrays are present above the critical point of $0,43 \mathrm{P} / \mathrm{P}_{0}$ (where $\mathrm{N}_{2}$ critical liquefaction can occur from). The isotherm idicates a high pore size uniformity centred at $9,2 \mathrm{~nm}$ and a microporous interconnectivity. The specific pore volume was found being $0,69 \mathrm{~cm}^{3} \cdot \mathrm{g}^{-1}$ the specific surface area was $540 \mathrm{~m}^{2} \cdot \mathrm{g}^{-1}$.

Intermediate Brij 58 (pore diameter - $d_{p}=44 \AA$ ) template gives similar structures with the following porosity characteristics: $0,75 \mathrm{~cm}^{3} \cdot \mathrm{g}^{-1}$ mesoporosity, and $700 \mathrm{~m}^{2} \cdot \mathrm{g}^{-1}$ specific surface area. The corresponding isotherm is shown in Figure 07 (b).

\section{Mesostructure formation (influence of processing parameters).}

The processing conditions, that is to say the successive residence time of the particles in a certain environment (temperature, humidity) before been collected on the filter, does influence the final morphology and the mesostructural organisation of the micelles. The diffraction diagrams corresponding to various studied conditions are given in Figure 08.
Furnace temperature. The role of the furnace is to allow for the particle to solidify by condensation. As a result of the short period of time in the furnace (typically less than 10s), the heat is mainly located at the particle surface since it is diffusion limited inside the particle. A peripherical condensed layer (outer shell) is then formed by condensation at the periphery. This shell is of outmost importance since it prevents the particles to coalesce when they found themselves in contact on the filter, and allows thus the particles to keep the spherical shape.

Such a coalescence phenomenon occurred for temperatures below $200^{\circ} \mathrm{C}$. In terms of micellar organisation, a too high temperature leads to less organised particles. The best organisation (highest and narrowest diffraction peaks) was found by allowing the particles to pass inside a first furnace at $150^{\circ} \mathrm{C}$ before entering the second furnace at $350^{\circ} \mathrm{C}$, suggesting that a progressive heat treatment is favourable to the mesoorganisation. A too high temperature tends to reduce the degree of organisation (see Figure 08), which is attributed to a too extended condensation of the inorganic phase. In view of these results, one may say that the heat treatment is necessary to obtain discrete particles with well organized mesoporosity (low dispersion in pore size distribution). The optimal temperature conditions are the following: a progressive temperature up to $350^{\circ} \mathrm{C}$ leads to the formation of the hard shell around the particles leaving the inside flexible enough to complete the organisation. The silica condensation inside the particle is naturally achieved by ageing.

Humidity. The versatility of the technique allows to change the composition of the carrying gas in the system. Recent studies on similar system as thin films demonstrated the critical role of the water relative pressure in the environment during evaporation ${ }^{19}$. At high humidity, water diffuses inside the system, promoting self assembly of the micelles by adjusting the micellar interfacial interaction with the inorganic matrix. This later wet condition can be applied to the aerosol generation by filling part of the drying chamber with water. In the present conditions of production, a relative humidity of $70 \%$ was measured in the chamber. The corresponding XRD diagram is given in Figure 08 and confirmed the positive role of water on the organisation during EISA, since it provided the most intense diffraction peak.

\section{Conclusion}

Preparation of mesoporous silica sub-micro spheres exhibiting high surface area, narrow pore size distribution, and hexagonal organization of cylindrical pores with CTAB or compact body centered cubic organization of spherical pores with copolymer blocks is possible by spray drying. Control on the pore size and organization is achieved by selecting the appropriate surfactant and by adjusting its composition. Also, careful control on the chemical parameters (initial sol composition, and $\mathrm{pH}$ ) and on the processing parameters (temperature and humidity) is required to promote self-assembly and to retain the spherical shape. The optimal conditions involved $\mathrm{pH}=1,2, \mathrm{CTAB} / \mathrm{TEOS}=0.18$, the presence of water and ethanol in the solution, a progressive heat treatment up to $350^{\circ} \mathrm{C}$ and a high relative pressure of water in the carrying gas.

\section{References}

1 J.S. Beck, J.C. Vartuli, W.J. Roth, M.E. Leonowicz, C.T. Kresge, KT. Schmitt, C.T.-W. Chu, K.H. Oison, E.W. Slieppard, S.B. McCulien, J.B. Higgins, J.L. Schlenker, J. Am.Chem. Soc., 1992, 114, 10834-10843

2 T. Barton, L. Bull, W. Klemperer, L. Douglas, B. McEnaney, M. Misono, P. Monson, G. Pez, G. Scherer, J. Vartuli, 0. Yaghi, Chem. Mater., 1999, 11, 2633-2656

3 J. Ying, C.P. Mehnert, M. S- Wong., Angew. Chem., Int. Ed. Eng, 1999, 38, 56-77

4 G. J. de A. A. Soler-Illia, E. L. Crepaldi, D. Grosso, D. Durand, C. Sanchez, Chem. Comm., 2002, 20, 2298-2299 
5 G. J. de A. A. Soler-Illia, C. Sanchez, B. Lebeau, J. Patarin, Chem. Rev., 2002, 102, 4093-413 8

6 S. Fôrster, T. Plantenberg, Angew. Chem.., Int. Ed. Engl., 2002, 41, 688-714

7 S.A. Bagshaw, E. Prouzet, T.J. Pinnavaia, Science, 1995, 269, 122

8 D. Zhao, Q. Huo, J. Feng, B.F. Chmelka, G.D. Stucky, J. Am. Chem. Soc., 1998, 120, 6024-6036.

9 Q. Huo, D. Margolese, D. Stucky, Chem. Mater, 1996, 8, 1147 1160

10 J. N. Israelachvili, D. J. Mitchell, B. W. Ninhatn, J. Chem. Soc. Faraday Trans. I, 72, 1525-1568

11 K. Fontell, A. Kahn, B. Lindstrëm, D. Maciejewska, S. PuangNgem, Colloid Polym.Sci., 1991, 269, 7, 727-742

12 Y. Lu, R. Ganguli, C. A. Drewien, M. T. Anderson, C. J. Brinker, W. Gong, Y. Guo, H. Soyez, B. Dunn, M. H. Huang, J. 1. Zink, Nature, 1997, 389, 364

13 A. Sayari, Chem. Mater., 1996, 8, 1840-1852

14 M. Raiinotidi, J. M. Seddon, Liq. Cryst., 1999, 0, 1-35

15 A. Corma, Chem. Rev., 1997, 97, 2373-2419

16 U. Ciesla, F. Schuth, Microporous mesoporous mater., 1999, 27, 131-149

17 P. Innocenzi, A. Martucci, M. Guglielmi, L. Arinelao, S. Pelli, G. C. Righini, G. C. Battaglin, J Non-Cryst. Solids, 1999, 259, 182-190

18 P. Innocenzi, A. Martucci, M. Guglielmi, A. Bearzotti, E. Traversa, Sens. Actualors, B, 2001, 76, 299-303

19 F. Cagnol, D. Grosso, G. J. de A. A. Soler-Illia, E. Crepaldi, F. Babonneau, H. Amenitsch, C. Sanchez, J. Mater. Chem., 2003, 61

20 D. Grosso, A.R. Balkenende, P.A. Albouy, A. Ayral, H. Amenitsch, F. Babonneau, Chem. Mater., 2001,13, 1848-1856

21 D. Grosso, F. Babonneau, G. J.de A. A. Soler Illia, P.-A. Albouy, H. Armnitsrh, Chem. Comm., 2001,748-749

22 D. Grosso, F. Babonneau, P.A. Albouy, H. Amenitscb, A.R. Balkenende, A. Brunet-Br-uneau, J. Rivory, Chem. Mater., 2001, 2, 931

23 J. Brinker, Y. Lu, A. Sellinger, H. Fan, Adv. Mater., 1999, 11, 7 , 579-585

24 D. Grosso, G. J.de A. A. Soler Illia, E. L. Crepaldi, B. Charleux, C. Sanchez, Adv. Funct. Mater., 2003, 13, No. 1, 37-42

25 C. J. Brinker and G. W. Scherer, Sol-gel science - The physics and chemistry of Sol-Gel Processing - Academic Press, 1990

26 T.T. Kodas and M. Hampden-Smith, Aerosol processing of materials - WILEY-VCH, 1999

27 P. Innocenzi, P. Falcaro, D. Grosso, F. Babonneau, J. Phys. Chem. $B, 2003$, in press

28 M. Kruk, M. Jaroniec, Chem. Mater., 2001,13, 3169-3183

29 M. T. Bore, S. B. Rathod, T. L. Ward, A. K. Datye, Langmuir, 2003, 19, 256-264 
